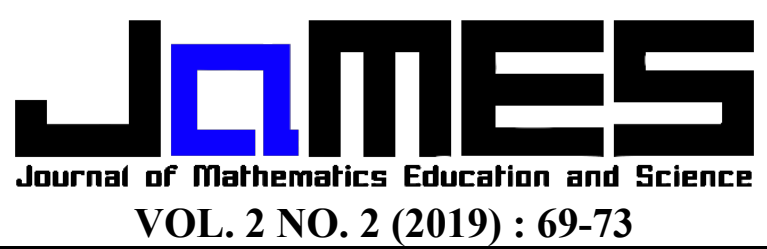

p-ISSN: 2621-1203 | https://doi.org/10.32665/james.v2i2.87

e-ISSN: 2621-1211

\title{
IMPLEMETASI APTITUDE TREATMENT INTERACTION TERHADAP HASIL BELAJAR EDUCATIONAL STATISTICS MAHASISWA PENDIDIKAN BAHASA INGGRIS IKIP PGRI BOJONEGORO
}

\author{
Dian Ratna Puspananda \\ IKIP PGRI Bojonegoro, bjn.air87@gmail.com \\ Received : 5 April 2019, Revised : 14 Oktober 2019, Accepted : 15 Oktober 2019 \\ (C) Mathematics Education Unugiri 2019
}

\begin{abstract}
This study aims to determine the effectiveness of the Aptitude Treatment Interaction learning model on the learning achievement of English education students in the subject of educational statistics. The instrument used is a subjective test. The sample used was 50 students, 22 students in the control class, and 28 students in the experiment class of the English Education study program at the Faculty of Language and Art Education at IKIP PGRI Bojonegoro. The data analysis used in this study is a t-test. The results of the study showed that the learning achievement of students of the English language education program became better after being given Aptitude Treatment Interaction in the Educational Statistics course.
\end{abstract}

Keywords: Aptitude Treatment Interaction (ATI), Learning Achievement, Educational Statistics

\begin{abstract}
Abstrak
Penelitian ini bertujuan untuk mengetahui keefektifan model pembelajaran Aptitude Treatment Interaction terhadap hasil belajar mahasiswa pendidikan bahasa inggris pada mata kuliah educational statistics. Instrumen yang digunakan adalah soal uraian. Sampel yang digunakan sebanyak 50 mahasiswa, 22 mahasiswa pada kelas kontrol dan 28 mahasiswa pada kelas eksperimen dari program studi Pendidikan Inggris Fakultas Pendidikan Bahasa dan Seni IKIP PGRI Bojonegoro. Analisis data yang digunakan dalam penelitian ini adalah $t$ - test. Hasil penelitian menunjukkan bahwa hasil belajar mahasiswa program studi pendidikan bahasa inggris menjadi lebih baik setelah diberikan pembelajaran Aptitude Treatment Interaction pada mata kuliah Educational Statistics.
\end{abstract}

Kata Kunci: Aptitude Treatment Interaction (ATI), Prestasi Belajar, Educational Statistics

\section{Pendahuluan}

Mata kuliah statistik merupakan mata kuliah wajib yang harus ditempuh mahasiswa perguruan tinggi. Statistika merupakan cabang ilmu matematika yang mempelajari tentang data, cara mengolahnya, dan menarik kesimpulan dari data tersebut. Menurut Budiyono [1], statistika adalah pengetahuan yang berhubungan dengan cara penyusunan data, penyajian data, dan penarikan kesimpulan mengenai suatu semesta (yang disebut populasi) berdasarkan data yang ada pada bagian dari semesta tadi.
Statistika sangat diperlukan dalam dunia penelitian. Hal ini sependapat dengan Sudjana [2], dunia penelitian atau riset, dimanapun dilakukan, bukan saja telah mendapat manfaat yang baik dari statistika tetapi sering harus menggunakannya. Pada kehidupan sehari - hari statistika sangat diperlukan. Hal ini dapat dilihat dari seseorang mampu memprediksi sesuatu dengan alat bantu statistik, misalnya data quick count untuk memprediksi hasil pemilu dari data yang dikumpulkan dari berbagai daerah, mengetahui jumlah dan pertumbuhan penduduk, bermanfaat dalam bidang ekonomi, teknologi, kedokteran, dan lain - lain. 
Educational Statistics adalah mata kuliah yang harus ditempuh mahasiswa prodi pendidikan Bahasa Inggris di IKIP PGRI Bojonegoro. Mata kuliah ini ditempuh pada semester V. Berdasarkan observasi yang dilakukan oleh peneliti, mata kuliah educational statistics adalah mata kuliah yang kurang diminati oleh mahasiswa. Sebanyak $80 \%$ mahasiswa menjawab mereka tidak tertarik dengan mata kuliah ini, dikarenakan mata kuliah educational statistics terlalu banyak memuat rumus, pengolahan data yang rumit, dan penyelesaian yang panjang. Menurut Sri Mulyono [3], sebenarnya anggapananggapan seperti itu harus dihilangkan, padahal dalam kehidupan sehari - hari statistika sangat berperan aktif dalam mengatur semua kegiatan yang kita lakukan. Ditegaskan pula dalam buku statistika ekonomi karangan beliau pada tahun 2003, bahwa dalam mempelajari statistika kita dibantu untuk menjelaskan hubungan antar variabel, membuat keputusan lebih baik, mengatasi perubahan - perubahan yang terjadi, dan membuat rencana serta ramalan. Namun pada kenyataannya mahasiswa masih banyak yang belum menyadari akan hal itu.

Berdasarkan hasil belajar mahasiswa pada mata kuliah educational statistics tahun akademik 2017/2018, 20\% mahasiswa mendapatkan nilai yang kurang memuaskan, bahkan ada mahasiswa yang tidak lulus pada mata kuliah tersebut. Persepsi awal mahasiswa yang menganggap mata kuliah educational statistics adalah mata kuliah yang sulit dan rumit, membuat minat dan motivasi mahasiswa untuk menempuh mata kuliah ini menjadi tidak maksimal. Mahasiswa terlihat tidak bersemangat dalam mengikuti perkuliahan. Akibatnya nilai yang mereka peroleh juga menjadi tidak optimal. Selain persepsi mahasiswa tentang mata kuliah educational statistics yang sulit dan rumit, ada kemungkinan suasana pembelajaran dalam kelas yang kurang efektif, dan model pembelajaran yang digunakan belum tepat. Educational Statistics seharusnya disajikan dengan cara yang menarik, menjelaskan dengan seksama tujuan mata kuliah ini diberikan, dan tugas perkuliahan lebih aplikatif, tidak sekedar teori, sehingga dengan cara ini diharapkan mahasiswa lebih terpacu motivasi belajarnya, sehingga hasil belajar juga diharapkan menjadi lebih baik.

Selain itu, mengetahui kemampuan mahasiswa adalah hal terpenting. Hal ini disebabkan setiap individu mempunyai kemampuan dan pengalaman yang berbedabeda. Apalagi dalam mata kuliah educational statistics yang mempunyai dasar kemampuan menghitung, sehingga sebagai pendidik kita harus tahu terlebih dahulu kemampuan yang dimiliki peserta didik. Hal ini dilakukan agar sebagai pendidik kita mampu memberikan pembelajaran yang tepat sasaran. Salah satu cara agar pembelajaran menjadi efektif dan tepat sasaran adalah dengan menerapkan model pembelajaran Aptitude Treatment Interaction. Aptitude Treatment Interaction dapat dijadikan sebagai suatu konsep atau pendekatan yang memiliki sejumlah strategi pembelajaran yang efektif digunakan untuk individu tertentu sesuai dengan kemampuannya masing-masing.

Menurut Cronbach (dalam Syafruddin Nurdin [4], bahwa Aptitude Treatment Interaction merupakan pendekatan yang berusaha mencari dan menemukan perlakuanperlakuan yang cocok dengan perbedaan kemampuan (aptitude) siswa. Makna esensial dari pembelajaran ATI adalah, ATI merupakan suatu konsep atau model yang berisikan sejumlah strategi pembelajaran yang efektif digunakan untuk peserta didik tertentu sesuai dengan perbedaan kemampuannya. Nampak bahwa pembelajaran ATI bertujuan untuk menciptakan dan mengembangkan suatu model pembelajaran yang benar-benar peduli dan memperhatikan antara kemampuan seseorang dengan pengalaman belajar atau khas dengan metode pembelajaran. Jadi, model pembelajaran ATI adalah suatu konsep atau model yang mencakup sejumlah strategi pembelajaran dengan mengembangkan kondisi pembelajaran yang efektif terhadap siswa yang mempunyai tingkat kemampuan yang berbeda.

Model pendekatan Aptitude Treatment Interaction (ATI) yang dikembangkan dalam penelitian ini terdiri dari empat tahapan: 1) 
Treatment awal pada siswa ini dengan menentukan dan menetapkan klasifikasi kelompok siswa berdasarkan tingkat kemampuan (aptitude/ability). 2) Pengelompokan siswa yang didasarkan pada treatment awal. Siswa di dalam kelas diklasifikasikan menjadi tiga kelompok yang terdiri dari siswa yang berkemampuan tinggi, sedang, dan rendah. 3) Memberikan perlakuan (Treatment) kepada masing - masing kelompok diberikan perlakuan (treatment) yang dipandang cocok / sesuai dengan karakteristiknya. Dalam pendekatan ini kepada siswa yang berkemampuan "tinggi" diberikan perlakuan (treatment) berupa self-learning melalui modul. Siswa yang memiliki kemampuan "sedang" diberikan pembelajaran secara konvensional regular teaching. Sedangkan kelompok siswa yang berkemampuan "rendah" diberikan perlakuan (treatment) dalam bentuk regular teaching + tutorial. Tutorial dapat diberikan oleh dosen educational statistics. 4) Achievement - Test diberikan kepada masing - masing kelompok kemampuan siswa (tinggi, sedang, dan rendah).

Kelebihan model pembelajaran Aptitude Treatment Interaction antara lain [5]: 1) Dapat meningkatkan motivasi belajar siswa, 2) Dapat meningkatkan pemahaman siswa terhadap materi pelajaran, 3) Guru dapat lebih memperhatikan kemampuan setiap siswa baik secara individu maupun kelompok, 4) Guru dapat memberikan treatment sesuai dengan kebutuhan siswa, 5) Siswa dapat mengoptimalkan prestasi belajarnya sesuai dengan kemampuannya.

Tujuan dari penelitian ini adalah untuk mengetahui apakah hasil belajar mahasiswa program studi pendidikan bahasa inggris menjadi lebih baik setelah diberikan pembelajaran Aptitude Treatment Interaction pada mata kuliah Educational Statistics.

\section{Metodologi Penelitian}

Penelitian ini merupakan penelitian eksperimental semu (quasi experimental). Menurut Budiyono [1], keseluruhan pengamatan yang ingin diteliti, berhingga atau tak berhingga, membentuk apa yang disebut populasi (universum). Sampel dalam penelitian ini adalah mahasiswa semester V program studi Pendidikan Bahasa Inggris IKIP PGRI Bojonegoro sejumlah 50 mahasiswa. Teknik sampling yang digunakan dalam penelitian ini adalah cluster random sampling.

Teknik analisis data yang digunakan adalah uji t dengan membandingkan rata-rata dua kelas yang dijadikan sebagai sampel penelitian. Data yang digunakan adalah nilai educational statistics mahasiswa pendidikan bahasa inggris setelah diberi perlakuan pembelajaran Aptitude Treatment Interaction. Uji prasyarat yang digunakan dalam penelitian ini adalah, uji normalitas menggunakan uji lilliefors, uji homogenitas menggunakan uji f, dan uji keseimbangan menggunakan uji t. Data yang digunakan untuk uji prasyarat adalah nilai kuis educational statistics mahasiswa.

\section{Hasil dan Pembahasan}

Data nilai kuis kelompok eksperimen (kelompok dengan pembelajaran ATI) dan kontrol (kelompok dengan pembelajaran konvensional) adalah sebagai berikut:

Tabel 1. Uji Normalitas Data Awal (dengan metode Lilliefors)

\begin{tabular}{cccc}
\hline Kelompok & Lhitung & Ltabel & $\begin{array}{c}\text { Keputusan } \\
\text { Uji }\end{array}$ \\
\hline Eksperimen & 0,163 & 0,173 & Ho diterima \\
\hline Kontrol & 0,163 & 0,173 & Ho diterima
\end{tabular}

Ket: $\mathrm{H}_{0}$ : Data berdistribusi normal

$\mathrm{H}_{1}$ : Data Tidak berdistribusi normal

Berdasarkan penghitungan uji normalitas sebelum diberi pembelajaran ATI pada tabel 1 menggunakan uji lilliefors dengan mengambil $\alpha=5 \%$, dapat diketahui bahwa pada kelompok eksperimen dan kontrol nilai $\mathrm{L}_{\text {hitung }}=$ 0,163, dan pada kelas kontrol nilai $\mathrm{L}_{\text {tabel }}=$ 0,173. Dari nilai $L_{\text {hitung masing - masing }}$ kelompok, baik eksperimen maupun kontrol lebih kecil daripada nilai $\mathrm{L}_{\text {tabel }}=0,173$, sehingga data pada kelompok tersebut berdistribusi normal. 
Tabel 2. Uji Homogenitas Data Awal (dengan uji F)

\begin{tabular}{cccc} 
Sampel & $\mathbf{F}_{\text {hitung }}$ & $\mathbf{F}_{\text {tabel }}$ & Keputusan uji \\
\hline $\begin{array}{c}\text { Kontrol dan } \\
\text { Eksperimen }\end{array}$ & 1,23 & 1,98 & $\mathrm{H}_{0}$ diterima \\
\hline
\end{tabular}

Ket: $\mathrm{H}_{0}$ : Variansi homogen

$\mathrm{H}_{1}$ : Variansi tidak homogen

Begitupun dengan uji homogenitas sebelum pembelajaran ATI menggunakan uji $\mathrm{F}$ dengan mengambil $\alpha=5 \%$, nilai $\mathrm{F}_{\text {hitung }}=1,23$ lebih kecil daripada nilai $\mathrm{F}_{\text {tabel }}=1,98$, sehingga menunjukkan data penelitian bersifat homogen, yaitu kedua kelompok memiliki variansi yang homogen.

Tabel 3. Hasil Uji Keseimbangan (dengan Uji t Dua Pihak)

\begin{tabular}{lccc} 
Sampel & $\mathbf{t}_{\text {hitung }}$ & $\mathbf{t}_{\text {tabel }}$ & Keputusan uji \\
\hline $\begin{array}{l}\text { Kontrol dan } \\
\text { Eksperimen }\end{array}$ & 0,137 & 1,960 & $\mathrm{H}_{0}$ diterima \\
\hline Ket: & & \\
Ho: Kedua kelompok memiliki rerata yang sama \\
H1: Kedua kelompok tidak memiliki rerata yang sama
\end{tabular}

Kedua kelompok penelitian yaitu kelompok eksperimen dan kontrol juga menunjukkan keadaan yang seimbang, hal ini ditunjukkan dengan nilai $t_{\text {hitung }}=0,137$ lebih kecil daripada nilai $t_{\text {tabel }}=1,960$.

Tabel 4. Uji Normalitas Data Akhir (dengan Metode Lilliefors)

\begin{tabular}{cccc}
\hline Kelompok & Lhitung & Ltabel & $\begin{array}{c}\text { Keputusan } \\
\text { Uji }\end{array}$ \\
\hline Eksperimen & 0,129 & 0,173 & Ho diterima \\
\hline Kontrol & 0,169 & 0,173 & Ho diterima \\
\hline Ket: $H_{0}$ : Data berdistribusi normal \\
H: Data Tidak berdistribusi normal
\end{tabular}

Berdasarkan penghitungan uji normalitas setelah diberi pembelajaran ATI pada tabel 1 menggunakan uji lilliefors dengan mengambil $\alpha=5 \%$, dapat diketahui bahwa pada kelompok eksperimen nilai $\mathrm{L}_{\text {hitung }}=0,129$, dan kontrol nilai $\mathrm{L}_{\text {hitung }}=0,169$, dan pada kelas kontrol nilai $\mathrm{L}_{\text {tabel }}=0,173$. Dari nilai $\mathrm{L}_{\text {hitung }}$ masing - masing kelompok, baik eksperimen maupun kontrol lebih kecil daripada nilai $\mathrm{L}_{\text {tabel }}$ $=0,173$, sehingga data pada kelompok tersebut berdistribusi normal.
Tabel 5. Uji Homogenitas Data Akhir (dengan Uji F)

\begin{tabular}{cccc} 
Sampel & F $_{\text {hitung }}$ & $\mathbf{F}_{\text {tabel }}$ & Keputusan uji \\
\hline $\begin{array}{c}\text { Kontrol dan } \\
\text { Eksperimen }\end{array}$ & 1,46 & 1,98 & $\mathrm{H}_{0}$ diterima \\
\hline \multicolumn{3}{c}{ Ket: $\mathrm{H}_{0}$ : Variansi homogen } \\
$\mathrm{H}_{1}$ : Variansi tidak homogen
\end{tabular}

Begitupun dengan uji homogenitas setelah pembelajaran ATI menggunakan uji $\mathrm{F}$ dengan mengambil $\alpha=5 \%$, nilai $F_{\text {hitung }}=1,46$ lebih kecil daripada nilai $\mathrm{F}_{\text {tabel }}=1,98$, sehingga menunjukkan data penelitian bersifat homogen, yaitu kedua kelompok memiliki variansi yang homogen.

Tabel 6. Hasil Uji Hipotesis (dengan uji t satu pihak)

\begin{tabular}{|c|c|c|c|}
\hline Sam & $t_{\text {hitung }}$ & $\mathbf{t}_{\text {tabel }}$ & Keputusan uji \\
\hline Eksperimen & 3,418 & 1,645 & $\mathrm{H}_{0}$ ditolak \\
\hline \multicolumn{4}{|c|}{$\begin{array}{l}\text { Ket: } \mathrm{H}_{0} \text { : Prestasi belajar dengan pembelajaran AT } \\
\text { tidak lebih baik dari prestasi belajar dengan } \\
\text { pembelajaran konvensional } \\
\mathrm{H}_{1} \text { : Prestasi belajar dengan pembelajaran ATI lebih } \\
\text { baik dari prestasi belajar dengan pembelajaran } \\
\text { konvensional }\end{array}$} \\
\hline
\end{tabular}

Pada uji hipotesis menggunakan uji $\mathrm{t}$ satu pihak yaitu pihak kanan, nilai thitung $=3,418$ lebih besar daripada nilai $t_{\text {tabel }}=1,645$, sehingga nilai $\mathrm{H}_{0}$ ditolak dan kesimpulan pada penelitian ini adalah hasil belajar mahasiswa program studi pendidikan bahasa inggris menjadi lebih baik setelah diberikan pembelajaran Aptitude Treatment Interaction pada mata kuliah Educational Statistics.

Hasil belajar mahasiswa program studi pendidikan bahasa inggris menjadi lebih baik setelah diberikan pembelajaran Aptitude Treatment Interaction pada mata kuliah Educational Statistics karena pada pembelajaran ini mahasiswa dilihat kemampuannya masing - masing khususnya pada ketrampilan pemahaman satistik dan kemampuan menghitungya, sehingga peneliti mampu memberikan treatment yang berbeda pada tiap - tiap individu.

Simpulan pada penelitian ini sejalan dengan penelitian yang dilakukan oleh Linda Fitasari bersama timnya yang dilakukan pada 
tahun 2014 dengan subjek siswa kelas VIII SMP Negeri 3 Panarukan, bahwa pembelajaran Aptitude Treatment Interaction mampu meningkatkan aktivitas dan hasil belajar siswa.

\section{Penutup}

Berdasarkan uraian di atas dapat disimpulkan bahwa prestasi belajar mahasiswa program studi pendidikan bahasa inggris menjadi lebih baik setelah diberikan pembelajaran Aptitude Treatment Interaction pada mata kuliah Educational Statistics.

Saran yang dapat diberikan adalah pembelajaran Aptitude Treatment Interaction bisa digunakan untuk alternatif pembelajaran pada mahasiswa khususnya pada mata kuliah statistik, karena pembelajaran ATI sangat memperhatikan kemampuan individu, sehingga dapat meningkatkan hasil belajar mahasiswa. Pembelajaran di kelas hendaknya juga menggunakan pembelajaran yang inovatif agar mahasiswa selalu bersemangat dalam mengikuti perkuliahan sehingga tujuan pembelajaran dapat tercapai.

\section{Referensi}

[1] Budiyono, "Statistika untuk Penelitian," Surakarta: UNS Press, (2009).

[2] Sudjana, "Metoda Statistika". Bandung: Tarsito, (2005).

[3] Mulyono, S., "Pendidikan bagi Anak Berkesulitan Belajar". Jakarta: Rineka Cipta, (2003).

[4] Nurdin, S., "Model Pembelajaran yang Memperhatikan Keragaman Individu Peserta Didik dalam Kurikulum Berbasis Kompetensi". Jakarta: Quantum Teaching, (2005).

[5] Setiani, Upaya Meningkatkan Prestasi Belajar Akuntansi dengan Menerapkan Model Pembelajaran Aptitude Tratment Interaction (ATI). Jupe UNS, vol. 1, no. 2 (2013). 